\title{
Penerapan Strategi Pembelajaran Task Based Language Learning Dalam Meningkatkan Keterampilan Menulis Teks Deskriptif Bahasa Perancis
}

\author{
Dinan Anshary, Yadi Mulyadi, \& Yuliarti Mutiarsih \\ Departemen Pendidikan Bahasa Perancis, FPBS, Universitas Pendidikan Indonesia \\ dinananshariy@gmail.com; yadimulyadi@upi.edu;yuliarti.mutiarsih@upi.edu
}

How to cite (in APA Style): Anshary, D., Mulyadi, Y., \& Mutiarsih, Y. (2019). Penerapan Strategi Pembelajaran Task Based Language Learning dalam Meningkatkan Keterampilan Menulis Teks Deskriptif Bahasa Perancis. Jurnal Pendidikan Bahasa dan Sastra, 19(2), 245-254. DOI: https://doi.org/10.17509/bs_jpbsp.v19i2.24789

Article History: Received (20 September 2019); Revised (29 September 2019); Accepted (1 October 2019) Journal homepage: http://ejournal.upi.edu./index.php/BS_JPBSP

Abstrak: Dewasa ini berkembang begitu banyak strategi pembelajaran yang dapat digunakan untuk menunjang kegiatan belajar mengajar agar lebih optimal. Salah satu strategi pembelajaran yang dapat diterapkan dalam keterampilan menulis adalah Task Based Language Learning (TBLL). Penelitian ini bertujuan untuk mengukur tingkat penguasaan mahasiswa terhadap keterampilan menulis teks deskriptif dalam bahasa Perancis sebelum dan sesudah penggunaan strategi pembelajaran TBLL; mengukur efektivitas penerapan strategi pembelajaran TBLL, dan; memperoleh informasi mengenai implementasi strategi pembelajaran TBLL. Penelitian ini menggunakan pendekatan kuantitatif dengan metode praeksperimen dan desain one group prates pascates. Temuan penelitian menunjukkan bahwa penggunaan strategi pembelajaran TBLL terbukti dapat meningkatkan keterampilan menulis teks deskriptif bahasa Perancis mahasiswa. Sementara itu, berdasarkan hasil perhitungan statistik, strategi TBLL terbukti efektif dengan adanya peningkatan nilai rata-rata yang diperoleh mahasiswa yaitu skor rata-rata prates sebesar 60,8 sementara skor rata-rata pascates meningkat menjadi 74,88. Kemudian berdasarkan analisis angket secara keseluruhan, penerapan strategi pembelajaran ini memberikan kontribusi positif terhadap pembelajaran keterampilan menulis teks deskriptif bahasa Perancis.

Kata kunci: task based language learning; keterampilan menulis; kuantitatif; strategi pembelajaran

\section{Implementation of Task Based Language Learning Strategies in Improving Writing Skills of Descriptive French Text}

\begin{abstract}
Today there are so many learning strategies to support teaching and learning activities. One of the learning strategies that can be applied in writing skills is Task Based Language Learning. This research aims to measure the level of student mastery of descriptive text writing skills before and after the use of Task Based Language Learning strategies; measure the effectiveness of the implementation of Task Based Language Learning, and; obtain information about the implementation of Task Based Language Learning. The method used in this research was a pre-experimental. Meanwhile, the research design was one-group pre-testpost-test design. The research findings explained that the use of Task Based Language Learning can improve students's descriptive text writing skills. This is proven by an increase in the average value obtained by students. The average score in the pre-test was 60.8 while the post-test average score increased by 74.88. Then based on the overall questionnaire data analysis, the application of this learning strategy contributed positively to the learning of descriptive French writing skills.
\end{abstract}

Keywords: task based language learning; writing skills; quantitative; learning strategies 


\section{PENDAHULUAN}

Perubahan dalam meningkatkan mutu dan kualitas pendidikan guru sangat dibutuhkan, karena guru bersinggungan langsung dengan proses transfer ilmu pengetahuan kepada siswa. Untuk itu, strategi yang dilakukan guru sangat tergantung dari kreativitas guru itu sendiri dalam menyampaikan isi materi kepada peserta didik. Fenomena-fenomena tersebut menjadi tantangan bagi peneliti untuk mendorong suatu perubahan dalam proses pembelajaran agar dapat menghasilkan prestasi belajar yang optimal.

Guru memiliki peran yang sangat vital dan fundamental dalam membimbing, mengarahkan, dan mendidik peserta didik dalam proses pembelajaran (Davies \& Ellison, 1992). Seorang guru tidak hanya dituntut sebagai pengajar yang bertugas menyampaikan materi pelajaran tertentu, tetapi juga harus berperan sebagai pendidik. Seorang pendidik dituntut untuk mampu memilih dan menerapkan strategi pembelajaran yang tepat bagi peserta didiknya. Oleh sebab itu, menurut Nasution (2016) dalam memilih strategi pembelajaran, pendidik harus memperhatikan keadaan atau kondisi peserta didik, bahan pelajaran serta sumber-sumber belajar yang ada agar penggunaan strategi pembelajaran dapat diterapkan secara efektif dalam menunjang keberhasilan belajar peserta didiknya. Strategi pembelajaran yang lebih memberi hasil yang baik bagi siswa adalah pembelajaran yang banyak melibatkan siswa berpikir, berbicara, berargumentasi dan mengutarakan gagasan-gagasannya (Tulus, 2004, p.77).

Dari empat keterampilan berbahasa, keterampilan menulis (production écrite) merupakan keterampilan yang dianggap sulit oleh para pembelajar bahasa dibandingkan dengan keterampilan lain. Klimova (2013) menyatakan bahwa "However, this skill is also one of the most difficult to acquire in a foreign language (FL). The reason is that in addition to learning strategies, writing requires a bigh proficiency of the target language." Pernyataan tersebut sesuai dengan apa yang dikemukakan oleh Sunendar, Cahyani, dan Mulyadi (2014, p.233) yaitu bahwa keterampilan menulis dalam Bahasa Asing dalam hal ini Bahasa Perancis tidaklah mudah untuk dikuasai oleh para pembelajar.

Sebuah studi dari De Wachter dan Heeren (2011) mengungkapkan bahwa masalah penulisan siswa paling sering terletak pada tingkat 1) struktur teks dan kohesi, 2) gaya dan, 3) ejaan. Pernyataan tersebut sesuai dengan pendapat Haider (2012) dan Hyland (2003) bahwa secara umum kesulitan dalam menulis terbagi dalam tiga hal yaitu linguistik, pengetahuan kognitif dan kemampuan psikologis seperti masalah motivasi dan kepercayaan diri siswa (Ahmed, \& Bidin, 2016). Ketiga permasalahan inilah yang membuat siswa sulit menuangkan ide mereka ke dalam teks (Bilal, Tariq, Din, Latif, \& Anjum, 2013; Dar \& Khan, 2015; Mahboob \& Talaat, 2008). Di samping itu, masalah lain yang sering ditemui adalah kesalahan dalam gramatika serta struktur teks yang tidak koheren dapat menghambat siswa dalam menuangkan ide tulisannya secara utuh karena jika tulisan tidak terstruktur maka proses penulisan dan pemahaman akan kontennya itu sendiri akan menjadi rumit (Alfaki, 2015; Quintero, 2008; Nik, Hamzah, \& Rafidee, 2010; Adas, \& Bakir, 2013). Menurut Indriyastuti (2018) permasalahan yang sering terjadi dalam penulisan teks deskriptif terutama dalam bahasa asing disebabkan karena ada beberapa aspek kebahasaan (misalnya: pemakaian kosakata yang tepat, tata bahasa yang baik dan benar, penggunaan ejaan dan tanda baca yang benar) yang sulit dikuasai oleh siswa.

Klimova (2013) menyatakan bahwa mahasiswa (undergraduates) masih memiliki kesulitan dalam menulis laporan hasil penelitian mereka seperti skripsi atau tesis bahkan mereka pun masih menemukan kesulitan ketika menulis artikel ilmiah 
singkat. Dari berbagai permasalahan tersebut, dapat ditarik benang merah bahwa masalah utama dalam keterampilan menulis adalah kesalahan dalam struktur teks dan sulitnya menuangkan ide kedalam tulisan secara utuh.

Agar tujuan pengajaran keterampilan menulis dapat tercapai dengan hasil yang optimal, pengajar dituntut untuk menggunakan strategi pembelajaran tertentu yang dapat mendorong minat serta memotivasi pembelajar agar keterampilan menulisnya dapat meningkat. Dewasa ini berkembang begitu banyak strategi pembelajaran yang dapat digunakan guna menunjang kegiatan belajar mengajar agar lebih optimal. Salah satu strategi pembelajaran yang dapat diterapkan dalam keterampilan menulis adalah TBLL.

Strategi pembelajaran TBLL dapat dikatakan efektif berdasarkan hasil penelitian yang ditemukan pada beberapa penelitian sebelumnya. Penelitian tersebut di antaranya : The Effect of Task Based Language Teaching on Writing Skills of EFL Learners in Malaysia (Ahmed \& Bidin, 2016) dan Penggunaan Metode Task based Learning untuk Meningkatkan Keterampilan Menulis Mahasiswa Bahasa Perancis (Kusnawati, 2014).

Berdasarkan uraian di atas, peneliti memandang perlu dilakukan suatu penelitian mengenai penerapan strategi TBLL untuk meningkatkan keterampilan menulis mahasiswa. Penelitian ini bertujuan untuk: (1) mengukur tingkat penguasaan mahasiswa terhadap keterampilan menulis teks deskriptif sebelum dan sesudah penggunaan strategi pembelajaran TBLL; (2) mengukur efektivitas penerapan strategi pembelajaran TBLL, dan (3) memperoleh informasi mengenai strategi pembelajaran TBLL

Strategi pembelajaran Task Based Language Learning ini pertama kali dikemukakan oleh Prabhu (1987) yang memiliki tiga kegiatan utama yaitu pre-task (preparatory), task (meaning focused and interactive process), dan post task (attending to form). Strategi ini kemudian dikembangkan lagi oleh Willis (1996) menjadi enam langkah yaitu pre task (imput, focus on meaning), task, assess task, planning, task presentation, post task language focus). Van den Branden (2011) menjelaskan bahwa TBLL mensyaratkan pembelajar lebih aktif dan memiliki peran utama dalam pembelajaran. Begitu pun menurut Nunan (2004) bahwa perbedaan utama yang terletak pada TBLL adalah strategi pembelajarannya yang lebih menekankan siswa untuk lebih aktif dalam berdiskusi selama pembelajaran baik dengan guru maupun sesama siswa melalui media tugas yang diberikan. Peran guru adalah memotivasi secara alami dan selalu memberi dorongan penuh kepada para siswa dalam proses implementasi pembelajaran task based.

\section{METODE}

Penelitian dilaksanakan di kampus Universitas Pendidikan Indonesia. Sampel dalam penelitian ini terdiri dari 25 mahasiswa semester 4 Departemen Pendidikan Bahasa Perancis UPI Tahun Ajaran 2018/2019. Peneliti memilih sampel ini karena mahasiswa semester 4 sedang mempelajari bahasa Perancis setingkat niveau A2. Penelitian ini menggunakan pendekatan kuantitatif, sebagaimana dijelaskan oleh Marczyk et al. (2005) bahwa "quantitative research involves studies that make use of statistical analysis to obtain their findings." (penelitian kuantitatif merupakan kajian yang menggunakan analisis statistik untuk mendapatkan temuannya). Sementara itu, metode yang digunakan adalah metode pra-eksperimen untuk melihat efektivitas penerapan strategi Task Based Language Learning untuk meningkatkan kemampuan menulis teks deskriptif bahasa Perancis. Terkait metode ini, menurut Creswell (2009) "the researcher studies a single group and provides an intervention during the experiment. This design does not have a control group to compare." Sehingga dapat disimpulkan bahwa peneliti melakukan eksperimen hanya terhadap satu grup tanpa ada grup pembanding lainnya. 
Sementara, desain penelitian yang digunakan peneliti adalah one-group pre-testpost-test design. Dalam desain penelitian ini, eksperimen hanya dilaksanakan terhadap satu grup tanpa adanya grup pembanding (Creswell, 2002).

\section{HASIL DAN PEMBAHASAN}

Tahap pertama yang dilakukan dalam penelitian ini merupakan tahap pre-test dilaksanakan terhadap 25 partisipan yang merupakan mahasiswa semester IV tahun akademik 2018/2019. Partisipan mengerjakan soal pre-test yang berupa soal keterampilan menulis teks deskriptif dengan tema "ma ville natale" dengan durasi pengerjaan 60 menit. Ujian pre-test ini dilakukan untuk mengetahui kemampuan menulis teks deskriptif partisipan sebelum diberikan treatment berupa strategi pembelajaran TBLL.

Tahap selanjutnya adalah pelaksanaan treatment atau perlakuan yang diadakan di pertemuan selanjutnya. Tahap ini berfokus pada aktivitas mahasiswa menyusun teks deskriptif secara berkelompok dengan tema "un lieu touristique". Tahapan treatment ini diberikan berdasarkan hasil analisis terhadap teks deskriptif mahasiswa pada tahap pre-test. Mahasiswa cenderung sulit mengembangkan ide dan menemukan kosakata yang beragam untuk mereka tuangkan ke dalam teks deskriptif, sehingga peneliti memberikan treatment untuk membantu mahasiswa mengatasi permasalahan tersebut. Tahapan dari pemberian treatment dijelaskan sebagai berikut ini:

\section{Pratugas}

Tahapan ini diawali dengan peneliti menjelaskan topik yang akan dibahas. Kemudian, peneliti membagi mahasiswa ke dalam beberapa kelompok karena teks deksriptif yang ditulis pada tahap treatment dikerjakan secara berkelompok. Peneliti memberikan teks yang mendeskripsikan sebuah tempat tertentu kepada mahasiswa, hal ini digunakan untuk menstimulasi ide dan kreativitas mahasiswa dalam menulis teks deskriptif dengan tema "un lieu touristique". Lalu, peneliti melakukan aktivitas yang dapat membantu mahasiswa mengingat kosakata terkait tema dengan cara memberikan 5 kosakata penting yang harus mahasiswa tulis ke dalam teks deskriptif mereka. Terakhir, mahasiswa membaca teks yang diberikan di awal, kemudian mencatat kosakata penting terkait dengan tema mendeskripsikan sebuah tempat.

2. Tugas

Mahasiswa mulai menyusun
teks deskriptif secara
berkelompok dengan tema " $u n$
lieu touristique". Peneliti berperan
mengawasi dan memotivasi
mahasiswa. Mahasiswa diberi
waktu untuk mempersiapkan
presentasi tugas tersebut pada
akhir pertemuan. Selanjutnya,
peneliti mengatur jalannya
proses presentasi.

3. Pascatugas

Dalam tahap presentasi, baik peneliti maupun mahasiswa saling memberikan komentar atau umpan balik terkait teks deskriptif yang sedang dipresentasikan oleh masing-masing kelompok. Lalu, mahasiswa mencatat kosakata menarik yang ditemukan pada tahap presentasi.

Setelah pelaksanaan treatment pembelajaran, selanjutnya adalah tahap pemberian tes akhir atau post-test. Soal posttest yaitu keterampilan menulis teks deskriptif dengan tema "un village inoubliable" dengan durasi 60 menit.

Dengan selesainya serangkaian tahap penelitian mulai dari tahap pre-test, treatment, hingga post-test, diperoleh data hasil 
tes untuk kemudian diolah oleh peneliti. Pengolahan dan analisis data menggunakan format penilaian baku yang telah disusun oleh Ministère de l'Éducation, du Loisir et du Sport-Quebec dalam Ouellet dan Martinet (2012) sehingga terdapat lima aspek penilaian yang menjadi acuan, yaitu: (1) Adaptation à la situation d'écriture; (2) Cobérence et cohésion du texte ; (3) Utilisation d'un vocabulaire approprie ; (4) Construction des phrases et ponctuations appropriees, dan ; (5) Respect des normes relatives à l'orthographe d'usage et à l'orthographe grammaticale.
Dengan demikian, peneliti dapat mendeskripsikan hasil pengolahan data sebagai berikut:

\section{1) Pre-test}

Data pre-test diolah untuk mengetahui kemampuan keterampilan menulis teks deskriptif bahasa Perancis dengan tema " $m a$ ville natale" sebelum adanya perlakuan atau treatment dengan strategi pembelajaran TBLL. Berikut ini adalah data hasil pemerolehan skor partisipan berdasarkan aspek penilaian di atas:

Tabel 1. Data Hasil Skor Pre-test

\begin{tabular}{|c|c|c|c|c|c|c|}
\hline \multirow[t]{2}{*}{ Partisipan } & \multicolumn{5}{|c|}{ Aspek Penilaian } & \multirow[t]{2}{*}{ Total (100) } \\
\hline & ASE & CCT & UVA & CPPA & RNRO & \\
\hline 001 & 12 & 12 & 8 & 8 & 8 & 48 \\
\hline 002 & 12 & 12 & 12 & 16 & 12 & 64 \\
\hline 003 & 8 & 12 & 8 & 8 & 8 & 44 \\
\hline 004 & 12 & 12 & 8 & 12 & 12 & 56 \\
\hline 005 & 8 & 12 & 16 & 12 & 12 & 60 \\
\hline 006 & 12 & 12 & 16 & 12 & 12 & 64 \\
\hline 007 & 8 & 12 & 12 & 12 & 12 & 56 \\
\hline 008 & 12 & 16 & 16 & 12 & 12 & 68 \\
\hline 009 & 12 & 12 & 8 & 8 & 12 & 52 \\
\hline 010 & 16 & 16 & 16 & 12 & 12 & 72 \\
\hline 011 & 12 & 12 & 16 & 12 & 12 & 64 \\
\hline 012 & 12 & 12 & 12 & 12 & 12 & 60 \\
\hline 013 & 16 & 12 & 16 & 12 & 12 & 68 \\
\hline 014 & 12 & 12 & 12 & 12 & 12 & 60 \\
\hline 015 & 12 & 12 & 16 & 12 & 12 & 64 \\
\hline 016 & 12 & 12 & 16 & 12 & 12 & 64 \\
\hline 017 & 12 & 12 & 12 & 12 & 12 & 60 \\
\hline 018 & 16 & 12 & 16 & 16 & 16 & 76 \\
\hline 019 & 12 & 12 & 16 & 12 & 12 & 64 \\
\hline 020 & 8 & 12 & 8 & 12 & 12 & 52 \\
\hline 021 & 12 & 12 & 12 & 12 & 12 & 60 \\
\hline 022 & 16 & 12 & 12 & 12 & 8 & 60 \\
\hline 023 & 12 & 12 & 16 & 12 & 12 & 64 \\
\hline 024 & 16 & 12 & 12 & 12 & 12 & 64 \\
\hline 025 & 12 & 12 & 8 & 12 & 12 & 56 \\
\hline umlah & 304 & 308 & 320 & 308 & 292 & 1.520 \\
\hline
\end{tabular}

Keterangan :

ASE : Adaptation à la situation d'écriture (Adaptasi terhadap situasi penulisan)

CCT : Cohérence et cohésion du texte (Kesinambungan dan keterkaitan teks)

UVA : Utilisation d'un vocabulaire approprié (Penggunaan kosakata yang tepat)

CPPA : Construction desphrases et ponctuations appropriées (Konstruksi kalimat dan tanda baca yang sesuai)

RNRO : Respect des normes relatives à l'orthographe d'usage et à l'orthographe grammaticale (Menaati norma-norma untuk ejaan dan ortografi gramatikal) 
Berdasarkan data tersebut, partisipan 018 memperoleh nilai tertinggi yaitu dengan skor 76 dari skor maksimal 100, sedangkan partisipan 001 memperoleh nilai terendah dengan skor 48 dari skor maksimal 100 .

\section{2) Post-test}

Pada tahap terakhir penelitian, peneliti memberikan tes akhir atau post-test setelah partisipan diberikan treatment (perlakuan) yaitu berupa keterampilan menulis teks deskriptif bahasa Perancis dengan tema "un village inoubliable" kepada 25 partisipan. Skor post-test ini dihimpun untuk memperoleh hasil kemampuan menulis teks deskriptif bahasa Prancis setelah adanya perlakuan atau treatment. Berikut ini adalah tabel data hasil pemerolehan skor post-test berdasarkan aspek penilaian Ministère de l'Éducation, du Loisir et du Sport - Quebec (Ouellet, \& Martinet, 2012).

Tabel 2. Data Hasil Skor Post-test

\begin{tabular}{|c|c|c|c|c|c|c|}
\hline \multirow[t]{2}{*}{ Partisipan } & \multicolumn{5}{|c|}{ Aspek penilaian } & \multirow[t]{2}{*}{ Total (100) } \\
\hline & ASE & CCT & UVA & CPPA & RNRO & \\
\hline 001 & 20 & 16 & 16 & 16 & 12 & 80 \\
\hline 002 & 20 & 20 & 16 & 12 & 12 & 80 \\
\hline 003 & 20 & 20 & 16 & 20 & 16 & 92 \\
\hline 004 & 16 & 16 & 16 & 12 & 12 & 72 \\
\hline 005 & 20 & 20 & 16 & 16 & 16 & 88 \\
\hline 006 & 20 & 16 & 16 & 16 & 16 & 84 \\
\hline 007 & 20 & 16 & 16 & 12 & 12 & 76 \\
\hline 008 & 20 & 16 & 16 & 12 & 12 & 76 \\
\hline 009 & 16 & 12 & 12 & 12 & 12 & 64 \\
\hline 010 & 20 & 16 & 20 & 16 & 16 & 88 \\
\hline 011 & 20 & 16 & 20 & 16 & 12 & 84 \\
\hline 012 & 16 & 16 & 16 & 12 & 12 & 72 \\
\hline 013 & 20 & 20 & 20 & 20 & 16 & 96 \\
\hline 014 & 20 & 16 & 20 & 16 & 12 & 84 \\
\hline 015 & 20 & 20 & 20 & 20 & 16 & 96 \\
\hline 016 & 20 & 20 & 20 & 16 & 12 & 88 \\
\hline 017 & 20 & 16 & 16 & 16 & 12 & 80 \\
\hline 018 & 20 & 16 & 16 & 16 & 12 & 80 \\
\hline 019 & 20 & 16 & 20 & 16 & 16 & 88 \\
\hline 020 & 16 & 12 & 16 & 12 & 12 & 68 \\
\hline 021 & 20 & 16 & 16 & 20 & 12 & 84 \\
\hline 022 & 16 & 20 & 16 & 16 & 16 & 84 \\
\hline 023 & 20 & 16 & 16 & 12 & 12 & 76 \\
\hline 024 & 20 & 20 & 16 & 16 & 12 & 84 \\
\hline 025 & 20 & 20 & 16 & 20 & 12 & 88 \\
\hline Jumlah & 480 & 444 & 432 & 388 & 332 & 1.872 \\
\hline
\end{tabular}

Keterangan :

ASE : Adaptation à la situation d'écriture (Adaptasi terhadap situasi penulisan)

CCT : Cohérence et cohésion du texte (Kesinambungan dan keterkaitan teks)

UVA : Utilisation d'un vocabulaire approprié (Penggunaan kosakata yang tepat)

CPPA : Construction des phrases et ponctuations appropriées (Konstruksi kalimat dan tanda baca yang sesuai)

$\mathrm{RNRO}$ : Respect des normes relatives à l'orthographe d'usage et à l'orthographe grammaticale (Menaati norma-norma untuk ejaan dan ortografi gramatikal)

Berdasarkan pemerolehan skor posttest tersebut, partisipan 013 dan 015 memperoleh skor tertinggi dengan nilai 96 dari skor maksimal 100 dan partisipan 009 memperoleh skor terendah dengan nilai 64 dari skor maksimal 100. 
Tabel 3. Distribusi Skor Pre-test dan Post-test

\begin{tabular}{|c|c|c|c|c|}
\hline No & Partisipan & Pre-test (x) & Post-test (y) & Gain $(d=y-x)$ \\
\hline 1 & 001 & 48 & 80 & 32 \\
\hline 2 & 002 & 64 & 80 & 16 \\
\hline 3 & 003 & 44 & 92 & 48 \\
\hline 4 & 004 & 56 & 72 & 16 \\
\hline 5 & 005 & 60 & 88 & 28 \\
\hline 6 & 006 & 64 & 84 & 20 \\
\hline 7 & 007 & 56 & 76 & 20 \\
\hline 8 & 008 & 68 & 76 & 8 \\
\hline 9 & 009 & 52 & 64 & 12 \\
\hline 10 & 010 & 72 & 88 & 16 \\
\hline 11 & 011 & 64 & 84 & 20 \\
\hline 12 & 012 & 60 & 72 & 12 \\
\hline 13 & 013 & 68 & 96 & 28 \\
\hline 14 & 014 & 60 & 84 & 24 \\
\hline 15 & 015 & 64 & 96 & 32 \\
\hline 16 & 016 & 64 & 88 & 24 \\
\hline 17 & 017 & 60 & 80 & 20 \\
\hline 18 & 018 & 76 & 80 & 4 \\
\hline 19 & 019 & 64 & 88 & 24 \\
\hline 20 & 020 & 52 & 68 & 16 \\
\hline 21 & 021 & 60 & 84 & 24 \\
\hline 22 & 022 & 60 & 84 & 24 \\
\hline 23 & 023 & 64 & 76 & 12 \\
\hline 24 & 024 & 64 & 84 & 20 \\
\hline \multirow[t]{2}{*}{25} & 025 & 56 & 88 & 32 \\
\hline & $n=26$ & $\sum x=1.520$ & $\sum y=1.872$ & $\sum d=352$ \\
\hline
\end{tabular}

Peneliti menghitung skor rata-rata (Mean) dari hasil pre-test dan post-test dengan rumus sebagai berikut ini:

- Nilai rata-rata pre-test atau variabel $x$

$\mathrm{M} x=\frac{\sum x}{n}=\frac{1.520}{25}=$

60.8

- Nilai rata-rata post-test atau variabel $y$ $\mathrm{M} y=\frac{\Sigma y}{n}=\frac{1.872}{25}=74.88$

Dari hasil perolehan tersebut, dapat diketahui bahwa terjadinya peningkatan pada keterampilan menulis teks deskriptif dengan penerapan strategi pembelajaran TBLL sebesar $14.08 \%$.

Tahap berikutnya adalah penentuan nilai koefisien signifikansi atau $t_{\text {bitung }}$ perbedaan nilai pre-test dan post-test. Data yang dibutuhkan untuk menentukan nilai $t_{\text {jitung }}$ adalah nilai rata-rata selisih pre-test dan post-test, $(M d)$, lalu nilai jumlah kuadrat deviasi $\left(\sum x^{2} d\right)$, dan jumlah sampel $(n)$ dengan rumus sebagai berikut:

$$
t=\frac{m d}{\sqrt{\frac{\sum x^{2} d}{n(n-1)}}}
$$

$$
\begin{gathered}
t=\frac{14.08}{\sqrt{\frac{3,525.6}{25(25-1)}}} \\
t=\frac{14.08}{\sqrt{5.87}} \\
t=\frac{14.08}{2.42} \\
t=5.81
\end{gathered}
$$

Berdasarkan data tersebut, peneliti menemukan bahwa nilai thitung sebesar 5.81 yang kemudian dibandingkan dengan nilai $t_{\text {tabel }}$ untuk menguji signifikansi dan hipotesis penelitian.

Sebelum menentukan tingkat signifikansi perbedaan nilai pre-test dan posttest, sebelumnya harus ditentukan dulu nilai derajat kebebasan $(d b)$ atau sampel $(n)$ dikurang 1 seperti pada rumus di bawah ini: $d b=n-1$

$d b=25-1$

$d b=24$

Berdasarkan perhitungan tersebut, peneliti menemukan bahwa nilai derajat kebebasan yaitu sebesar 24. Setelah itu, peneliti membandingkan nilai $t_{\text {hitung }}$ dan $t_{\text {tabel }}$ untuk menemukan nilai signifikansi 
perbedaan nilai pre-test dan post-test. Dalam penelitian ini, peneliti menggunakan taraf signifikansi sebesar $1 \%$ atau 0.01 , maka diperoleh nilai $t_{\text {tabel }}$ sebesar 2.79.

Sesuai dengan hasil perhitungan yang sudah didapatkan yaitu thitung sebesar 5.81 dan nilai $t_{\text {tabel }} 2.797$ maka dapat disimpulkan bahwa $t_{\text {bitung }}>t_{\text {tabel }}\left(t_{\text {hitung }}\right.$ lebih besar dari $\left.t_{\text {tabel }}\right)$ yang artinya ada perbedaan yang signifikan antara data pre-test dan data post-test maka hipotesis kerja $\left(H_{i}\right)$ diterima dan hipotesis nol $\left(H_{0}\right)$ ditolak. Dari hasil tersebut maka peneliti dapat menyimpulkan bahwa penerapan strategi pembelajaran TBLL efektif untuk meningkatkan kemampuan menulis teks deskriptif bahasa Perancis mahasiswa semester 4 Departemen Pendidikan Bahasa Perancis UPI tahun ajaran 2018/2019.

Sementara berdasarkan analisis data angket secara keseluruhan, peneliti dapat menyimpulkan bahwa penerapan strategi pembelajaran TBLL memberikan kontribusi positif terhadap pembelajaran keterampilan menulis teks deskriptif bahasa Perancis Nivean A2 Hal ini dibuktikan dengan sebanyak $90,4 \%$ partisipan merasa terbantu dengan treatment atau perlakuan khusus yang diberikan terkait strategi pembelajaran ini. Salah satu kelebihan dari strategi TBLL adalah adanya tahap presentasi tugas pada akhir pertemuan, hal ini ditanggapi sangat positif oleh $82,4 \%$ partisipan yang merasakan manfaat dari tahapan presentasi itu sendiri. Di samping itu, sebanyak $84 \%$ partisipan merasa bahwa tahapan presentasi memotivasi mereka untuk mempersiapkan tugas menulis teks deskriptif dengan lebih baik.

Hasil penelitian ini menunjukkan bahwa strategi pembelajaran TBLL efektif untuk meningkatkan kemampuan menulis mahasiswa, hal tersebut didukung oleh penelitian sebelumnya yang dilakukan oleh Kusnawati (2014). Temuan penelitiannya menunjukkan bahwa penggunaan metode pembelajaran berbasis tugas (task based learning) dapat meningkatkan keterampilan menulis mahasiswa. Peningkatan tersebut terlihat pada pemahaman dan penguasaan materi mahasiswa yang menjadi lebih baik dari sebelumnya. Hal ini dibuktikan dengan peningkatan nilai rata-rata yang diperoleh mahasiswa berdasarkan hasil postes, yakni 6,3 pada siklus I dan 7,2 pada siklus II. Selain itu, menurut Kusnawati (2014) terjadi pula peningkatan proses pembelajaran Keterampilan Menulis yang ditandai dengan berkurangnya kepasifan mahasiswa dan peningkatan partisipasi mahasiswa dalam kegiatan pembelajaran yang bermakna. Penelitian yang dilakukan oleh Ahmed dan Bidin (2016) pun menunjukkan bahwa strategi ini efektif untuk membuat mahasiswa bersikap aktif selama proses pembalajaran.

\section{SIMPULAN}

Berdasarkan penelitian yang telah dilaksanakan selama bulan maret hingga juni 2019 dapat ditarik simpulan bahwa: (1) Keterampilan menulis teks deskriptif bahasa Perancis mahasiswa semester 4 Departemen Pendidikan Bahasa Perancis UPI setelah menggunakan strategi TBLL mengalami peningkatan jika dibandingkan sebelum menggunakan strategi TBLL. Peningkatan keterampilan menulis teks deskriptif tersebut dapat dilihat dari hasil perhitungan data yang diperoleh. Pada saat pre-test, nilai tertinggi yang didapatkan adalah 76 dan nilai terendah adalah 48. Di samping itu, nilai rata-rata pre-test yang diperoleh siswa adalah 60,8. Sementara, keterampilan menulis teks deskriptif bahasa Perancis setelah menggunakan strategi TBLL memperoleh nilai tertinggi 96 , nilai terendah 64 serta nilai rata-rata 74,8. (2) strategi TBLL efektif digunakan dalam meningkatkan keterampilan menulis teks deskriptif mahasiswa semester 4 Departemen Pendidikan Bahasa Perancis UPI. Hal ini dibuktikan dengan mencari perbandingan antara $t_{\text {bitung }}$ dengan $t_{\text {tabel }}$. Diperoleh nilai $t_{\text {tabel }}$ dengan nilai derajat kebebasan $(d b) 24$ dan taraf signifikansi sebesar $1 \%$ atau 0.01 adalah sebesar 2.79 sedangkan nilai $t_{\text {bitung }}$ pada penelitian ini adalah sebesar 5,81. Maka, $\boldsymbol{t}_{\text {hitung }}>\boldsymbol{t}_{\text {tabel }}$ yaitu $5,81>2,79$. Dengan demikian, peneliti menyimpulkan bahwa hipotesis kerja dalam penelitian ini dapat diterima karena nilai $t_{\text {bitung }}$ 
lebih besar dibandingkan dengan $t_{\text {tabel. }}$ Dengan terbuktinya hipotesis kerja ini, terbukti bahwa strategi TBLL efektif untuk meningkatkan keterampilan menulis teks deskriptif bahasa Perancis.Terakhir, merujuk pada hasil perolehan angket, peneliti menyimpulkan bahwa tanggapan siswa mengenai penerapan strategi TBLL dalam pembelajaran menulis teks deskriptif bahasa Perancis terbilang positif. Hal ini dibuktikan dengan sebanyak 90,4\% partisipan merasa terbantu dengan treatment atau perlakuan khusus yang diberikan terkait strategi pembelajaran ini. Salah satu kelebihan dari strategi TBLL adalah adanya tahap presentasi tugas pada akhir pertemuan, hal ini ditanggapi sangat positif oleh $82,4 \%$ partisipan yang merasakan manfaat dari tahapan presentasi itu sendiri. Di samping itu, sebanyak $84 \%$ partisipan merasa bahwa tahapan presentasi memotivasi mereka untuk mempersiapkan tugas menulis teks deskriptif dengan lebih baik.

\section{DAFTAR RUJUKAN}

Adas, D., \& Bakir, A. (2013). Writing difficulties and new solutions: Blended learning as an approach to improve writing abilities. International journal of bumanities and social science, 3(9), 254266.

Ahmed, R. Z., \& Bidin, S. J. B. (2016). The Effect of Task Based Language Teaching on Writing Skills of EFL Learners in Malaysia. Open Journal of Modern Linguistics, 6, 207218.

http://dx.doi.org/10.4236/oiml.20 16.63022

Alfaki, I. M. (2015). University students' English writing problems: diagnosis and remedy. International Journal of English Language Teaching, 3(3), 4052.

Bilal, H. A., Tariq, A. R., Din, N., Latif, H., \& Anjum, M. N. (2013). Investigating the problems faced by the teachers in developing English writing skills. Asian Journal of Social Sciences and Humanities, 2(3), 238-244.

Creswell, J. W. (2002). Educational research: Planning, conducting, and evaluating quantitative (pp. 146-166). Upper Saddle River, NJ: Prentice Hall.

Dar, M. F., \& Khan, I. (2015). Writing anxiety among public and private sectors Pakistani undergraduate university students. Pakistan Journal of Gender Studies, 10(1), 121-136.

Davies, B., \& Ellison, L. (1992). School Development Planning. Essex: Longma Group U.K.Ltd.

De Wachter, L., \& Heeren, J. (2011). Entrylevel academic language skills. A needs analysis of language problems and remedy of first year university students at the University of Leuven. Retrieved from: https://ilt.kuleuven.be/ cursus/docs/Behoefteanalyse Taal VaST.pdf

Indriyastuti, A. (2018). Peningkatan Keterampilan Menulis' Descriptive Text'dengan Menggunakan Media'Magic Card'pada Mata Pelajaran Bahasa Inggris di Kelas X (Improving the Descriptive Text Writing Skill Using Magic Cards in English Class in 10th Grade). Lensa: Kajian Kebabasaan, Kesusastraan, dan Budaya, 8(1), 56-74.

Klimova, B. (2013). Constraints and difficulties in the process of writing acquisition. Journal Procedia Social and Behavioral Sciences. 2nd World Conference on Design, Arts and Education DAE-2013.

Kusnawati, T.(2014). Penggunaan metode Task-based Learning untuk Meningkatkan Keterampilan Menulis Mahasiswa. Jurnal Pendidikan Bahasa dan Sastra, 14(1), 93-108.

doi: https://doi.org/10.17509/bs i pbsp.v14i1.713

Mahboob, A., \& Talaat, M. (2008). English language teachers and teacher education in Pakistan. Global English teacbing and teacher education: Praxis \& possibility, 3-25. 
Jurnal Pendidikan Bahasa dan Sastra, Volume 19, Nomor 2, Oktober 2019, pp. 245 - 254

Nasution, H. F. (2016). Hubungan metode mengajar dosen, keterampilan belajar, sarana belajar dan lingkungan belajar dengan prestasi belajar mahasiswa. Jurnal ilmu pendidikan, 8(1).

Nik, Y. A., Hamzah, A., \& Rafidee, H. (2010). A comparative study on the factors affecting the writing performance among bachelor students. International Journal of Educational Research and Technology, 1(1), 54-59.

Nunan, D. (2004). Task -Based Teaching. Cambridge: Cambridge University Press.

Ouellet, M., \& Martinet, M. (2012). Encadement des stagiaires: de la formation à l'enseignement. Raport d'évaluation de programme. Ministère de l'Éducation, du Loisir et du Sport: Québec. BENITES, LC O professor-colaborador no Estágio Curricular Supervisionado em Educaşão Física: perfil, papel e potencialidades.
Prabhu, N. S. (1987). Second language pedagogy (Vol. 20). Oxford: Oxford University Press.

Quintero, L. M. (2008). Blogging: A way to foster EFL writing. Colombian Applied Linguistics Journal 10 (1), 74

Sunendar, D., Cahyani, D. \& Mulyadi, Y. (2014). Implementasi Metode Ecriture Créative Berbasis Budaya Lokal Untuk Meningkatkan Keterampilan Menulis Bahasa Perancis Level B1 DELF. Jurnal Pendidikan Bahasa dan Sastra, 14(2), 229-240.

doi: https://doi.org/10.17509/bs j pbsp.v14i2.721

Tulus, T. (2004). Peran Disiplin pada Perilaku dan Prestasi Belajar. Jakarta: Grasindo

Van den Branden, K. (2011). Task-based language teaching: from theory to practice. Cambridge: Cambridge University Press.

Willis, J. (1996). A framework for task-based learning. Harlow, England: Longman. 